\title{
Business Intelligence Systems in the Holistic Infrastructure Development Supporting Decision-Making in Organisations
}

\author{
Celina M. Olszak and Ewa Ziemba \\ University of Economics, Katowice, Poland \\ olszak@ae.katowice.pl ewa@ae.katowice.pl
}

\begin{abstract}
The paper aims at analysing Business Intelligence Systems (BI) in the context of opportunities for improving decision-making in a contemporary organisation. The authors - taking specifics of a decision-making process together with heterogeneity and dispersion of information sources into consideration - present Business Intelligence Systems as some holistic infrastructure of decisionmaking. It has been shown that the BI concept may contribute towards improving quality of decision-making in any organisation, better customer service and some increase in customers' loyalty. The paper is focused on three fundamental components of the BI systems, i.e. key information technologies (including ETL tools and data warehouses), potential of key information technologies (OLAP techniques and data mining) and BI applications that support making different decisions in an organisation. A major part of the paper is devoted to discussing basic business analyses that are not only offered by the BI systems but also applied frequently in business practice.
\end{abstract}

Keywords: Business Intelligence, data mining, OLAP, ETL, business decision-making, knowledge management

\section{Business Intelligence Systems in Decision-Making}

Decision-making in management has always involved utilisation of different information assets. Contemporary economic conditions show that organisations are more frequently made to use external, dispersed and semi-structured sources of information.

In today's decision-making, it is necessary to reach for information. However, it is knowledge that has to be mainly looked for. Knowledge provides foundations for effective business activities. Procedural knowledge (explaining how to perform tasks and follow procedures) should be accompanied by declarative knowledge (indicating what has to be done), semantic knowledge (depicting relations between facts) and casuistic knowledge (that refers to some cases from the past). So-called tacit knowledge is a large part of knowledge in an organisation. Organisations

Material published as part of this journal, either on-line or in print, is copyrighted by the Informing Science Institute. Permission to make digital or paper copy of part or all of these works for personal or classroom use is granted without fee provided that the copies are not made or distributed for profit or commercial advantage AND that copies 1) bear this notice in full and 2) give the full citation on the first page. It is permissible to abstract these works so long as credit is given. To copy in all other cases or to republish or to post on a server or to redistribute to lists requires specific permission and payment of a fee. Contact Publisher@InformingScience.org to request redistribution permission. that are interested to use knowledge in decision-making are forced to work out procedures that enable them to transform tacit knowledge into explicit knowledge. In this situation, organisations find it necessary to create repositories of knowledge and knowledge management systems, simultaneously finding the way to match them with decision support systems. 
Nowadays, different groups of people participate in decision-making (stakeholders, customers, suppliers, etc.). The scope of a particular decision is in many cases of global nature. Regional and international interdependencies require wider exchange of information and knowledge sharing, and better coordination of activities undertaken in contrast to everything that took place in the past (Viehland, 2005).

Dispersion of information assets and their frequently tacit nature results in some insufficiency of the up-to-date models of information management used for decision-making (Bui 2000; Kersten, 2000; Power, 2001). Organisations that are interested to improve quality of decision-making, image or quality of partner service should incline towards the development of information technology infrastructure that will represent a holistic approach to business operations, customers, suppliers, etc. (Wells, \& Hess, 2004). Theory and practice show that the above-mentioned requirements are largely met by Business Intelligence (BI) systems (Gray, 2003; Liautaud, \& Hammond, 2002; Olszak, \& Ziemba, 2004; Turban, \& Aronson, 1998).

BI systems are referred to as an integrated set of tools, technologies and programme products that are used to collect, integrate, analyse and make data available (Reinschmidt, \& Francoise, 2000). The systems in question are to support decision-making on all management levels. They differ from traditional Management Information Systems by - first of all - a wider subject range, multivariant analyses of semi-structured data that come from different sources and their multidimensional presentation. The BI systems contribute to optimising business processes and resources, maximising profits and improving proactive decision-making. The systems in question may be utilised while creating various applications within finance, monitoring of competition, accounting, marketing, production, etc. The most important components of the BI infrastructure consist of (Figure 1):

- key information technologies that are related with data acquisition and storing i.e. ETL (Extraction-Transformation-Load) tools and data warehouses;

- information technologies potential that mainly refers to versatile analyses of data, and presentation of data, i.e. OLAP (On-Line Analytical Processing) techniques and data mining; and

- BI applications that support making various decisions on production, sales, competition monitoring, finance, etc (Kalkaota, \& Robinson, 1999).

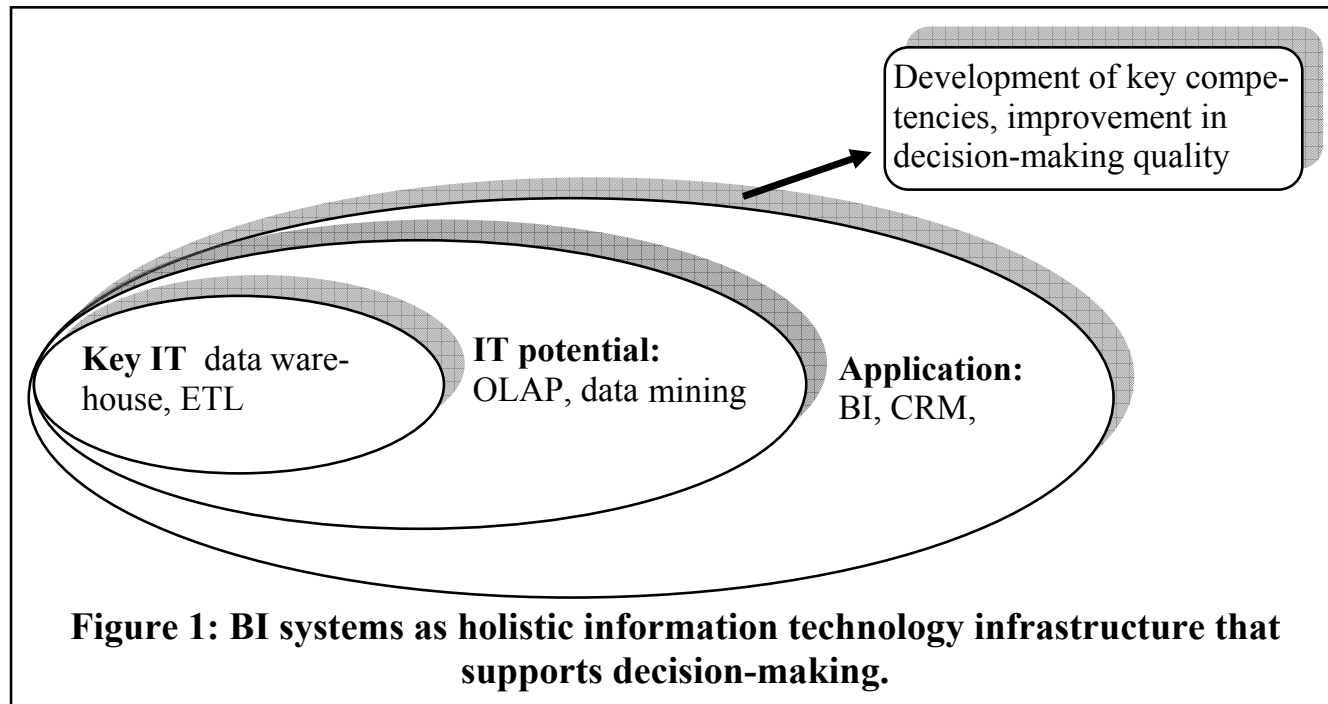

Source: (Kalakota, \& Robinson, 1999). 


\section{Key Information Technologies of Business Intelligence}

Contemporary organisations do not face problems resulting from the lack of information. They are rather concerned because of information overload and information dispersion. Wishing to make effective decisions, it is necessary to use different sources of information and then, to integrate information required. Nowadays, data warehouses are thought to be major technologies that support heterogenic decision-making environment. They are collections of subject-oriented, integrated, non-volatile, historical data that support organisational decisions (Gray, \& Watson, 1998; Inmon, 1992). A design of a data warehouse may take a star schema, snowflake schema or fact constellation. In case of a star schema, factographic data are stored in the central table surrounded by reference tables including data on particular dimensions that are necessary while making decisions. In the snowflake schema, each dimension may have several own dimensions. It means that reference tables are not denormalised. A schema of a constellation type is an in-between solution. Some tables are subject to denormalisation and others to normalisation.

A data warehouse is predominantly used to store detailed summary data and metadata. Detailed data concern, for instance, sales or production volume in a given period. In order to increase effectiveness of queries, data in a data warehouse are subject to aggregation. Data e.g. on sales may be aggregated in a geographical dimension, a time period dimension or a product line dimension, etc. On the other hand, metadata include information on data themselves. They facilitate a process of extracting, transforming and loading data through presenting sources of data in the layout of data warehouses. Metadata are also used to automate summary data creation and queries management.

Utility of data warehouses largely depends on the quality of their data stored. ETL tools are responsible for extracting, transforming and loading of data.

Extraction involves obtaining access to data originating from different sources (databases, text files, HTML and XML documents or e-mail). As a result of extraction, data are usually stored in the relational database significantly facilitating further data processing at the transformation stage. Software that carries out extraction of data should also record information including extraction time, structure of source data, data place of origin, etc.

Transformation of data is considered to be the most complex stage of the ETL process. The process is usually performed by means of traditional programming languages, script languages or the SQL language. Data transformation means data unification, calculation of necessary aggregates, identification of missing data or duplication of data. Data transformation rules may concern principles of physical data structure unification, business principles that ensure compatibility with a modelled domain and business principles that ensure semantic compatibility between related data.

Data loading involves providing data warehouses with data that are aggregated and filtered. Since the process in question frequently involves switching the system into the offline mode, it is particularly important to minimise the time that is necessary to transfer data.

Depending on the scope of realised functions ETL tools may be divided into four categories (Meyer, 2001):

- EtL tools that stress extraction and loading of data;

- eTL or ETl that prefer specific types of input or output data (e.g. they function exclusively in text files or specific database formats), and reliable and fast functions of data processing and transforming;

- ETL tools that realise a process of data transformation relatively well, although they do not offer servicing of numerous typical data formats; and 
- eTL tools that are complete integration environments equipped with numerous solutions that support users while constructing ETL systems.

ETL solutions available on the market (including e.g. SAS Q, DataStage EX, Oracle Warehouse Builder, DataMirror Transformation Server, Microsoft Data Transformation Services) differ by, inter alia, access to data, algorithms of data processing, components used to filter and search data. A selection of an appropriate solution out of all the already mentioned products is not easy. The organisation's information resources and needs, requirements set by already existing data structure and financial means play a major role while deciding which solution is to be chosen.

\section{Potential of Key Business Intelligence Technologies}

Heterogeneity of a decisional environment stimulates organisations to look for effective techniques of analysing and drilling data. Currently, OLAP and data mining techniques offer such potential.

OLAP tools are mainly aimed at interactive report generation according to user's pre-defined criteria (dimensions), and optimisation of searching huge data files by means of automatic generation of SQL queries. They allow for carrying out complex analyses of company performance, customer relations, product profitability, etc. They also provide answers of the 'who?', 'what?', 'when?', 'what if?' and 'why?' type. Multi-variant analyses carried out on historical data (stored in data warehouses) allow for predicting future, setting trends, customer behaviour, and competition behaviour. Their effective realisation enables organisations to detect weaknesses, threats and hidden opportunities and chances (Olszak, \& Ziemba, 2003).

Data mining involves discovering various patterns, generalisations, regularities and rules in data resources (Hauke, Owoc, \& Pondel, 2003; Kantardzic, 2002; Poul, Gautman, \& Balint, 2003). Knowledge resulting from data mining may be utilised in two dimensions, i.e. to predict (prediction), and to describe (description) reality. Prediction involves using already known variables to predict future. For instance, a prognostic model help - on the basis of historical data - to assess incomes within particular assortment groups of products and customer groups. On the other hand, reality description by means of data mining techniques enables to create clear and understandable for a human being interpretation of knowledge mined from data in the form of graphs, formulas, rules and tables. For instance, mined knowledge on customers' purchases may be used to support decisions concerning pricing policies (Moss, \& Alert, 2003; Reinschmidt, \& Francoise, 2000)

A selection of data mining methods requires determining whether interpretation of data interdependencies or prediction is being looked for. Data mining is the most frequently associated with the following types of activities:

- in case of descriptive data mining - associations (discovering associations); discovering relations in the sequence, grouping and finding exceptions and deviations.; and

- in case of predictive data mining - classification, regression or analysis of time series; for users it is very important that a way of presenting data is adequate to their perception abilities; such potential is offered by text, graphic and multimedia interface.

\section{Business Intelligence Applications}

BI systems beneficiaries include a wider and wider group of users starting from specialists in controlling, financial reporting and finance, through salespeople, up to members of the board (Rasmussen, Goldy, \& Solli, 2002). Sectors that use BI systems most frequently include trading companies, insurance companies, banks and a financial sector, telecommunications and manufacturing companies (see Table 1). 
Table 1. Business Intelligence application areas

\begin{tabular}{|c|c|}
\hline BI applications & Objectives \\
\hline Retail industry & $\begin{array}{l}\text { - Forecasting. Using scanning data to forecast demand and based on the forecast, } \\
\text { to define inventory requirements more accurately } \\
\text { - Ordering and replenishment. Using information to make faster decisions about } \\
\text { items to order and to determine optimum quantities } \\
\text { - Marketing. Providing analyses of customer transactions (what is selling, who is } \\
\text { buying) } \\
\text { - Merchandising. Defining the right merchandise for the market at any point in } \\
\text { time, planning store level, refine inventory } \\
\text { - Distribution and logistics. Helping distribution centres manage increased vol- } \\
\text { umes. Can use advance shipment information to schedule and consolidate in- } \\
\text { bound and outbound freight } \\
\text { - Transportation management. Developing optimal load consolidation plans and } \\
\text { routing schedules } \\
\text { Inventory planning. Helping identify the inventory needed level, ensure a given } \\
\text { grade of service }\end{array}$ \\
\hline Insurance & $\begin{array}{l}\text { - Claims and premium analysis. The ability to analyze detailed claims and pre- } \\
\text { mium history by product, policy, claim type, and other specifics } \\
\text { - Customer analysis. Analyze client needs and product usage patterns, develop } \\
\text { marketing programs on client characteristics, conduct risk analysis, improving } \\
\text { client service } \\
\text { - Risk analysis. Identify high-risk market segments and opportunities in specific } \\
\text { segments, relate market segments, reduce frequency of claims }\end{array}$ \\
\hline $\begin{array}{l}\text { Banking, finance } \\
\text { and securities }\end{array}$ & $\begin{array}{l}\text { - Customer profitability analysis. Determinate the overall profitability of individ- } \\
\text { ual customer, current and long term, provide the basis for high-profit sales and } \\
\text { relationship banking, maximize sales to high-value customers, reduce costs to } \\
\text { low-value customers, provide the means to maximize profitability of new prod- } \\
\text { ucts and services } \\
\text { - Credit management. Establish patterns of credit problem progression by cus- } \\
\text { tomers class and type, warn customers to avoid credit problems, to manage } \\
\text { credit limits, evaluate of the bank's credit portfolio, reduce credit losses } \\
\text { - Branch sales. Improve customer service and account selling, facilitate cross } \\
\text { selling, improve customer support, strengthen customer loyalty }\end{array}$ \\
\hline Telecommunications & $\begin{array}{l}\text { - Customer profiling and segmentation. Determine high-profit product profiles } \\
\text { and customer segments, provide detailed, integrated customer profiles, develop } \\
\text { of individualized frequent-caller programs, determine future customer needs } \\
\text { - Customer demand forecasting. Forecast future product needs or service activity, } \\
\text { provide basis for churn analysis and control for improving customer retention }\end{array}$ \\
\hline $\begin{array}{l}\text { Manufacturing in- } \\
\text { dustry }\end{array}$ & $\begin{array}{l}\text { - Sales. Provide analyses of customer-specific transaction data } \\
\text { - Forecasting. Forecast demand, define inventory requirements } \\
\text { - Ordering and replenishment. Order optimum quantities of items } \\
\text { - Purchasing. Helping distribution centres manage increased volumes. } \\
\text { - Distribution and logistics. Can use advance shipment information to schedule } \\
\text { and consolidate inbound and outbound freight } \\
\text { - Transportation management. Developing optimal load consolidation plans and } \\
\text { routing schedules } \\
\text { - Inventory planning. Identify the inventory level needed, ensure a given grade of } \\
\text { service }\end{array}$ \\
\hline
\end{tabular}

Source: based on (Reinschmidt, \& Francoise, 2000). 
Efforts undertaken to develop BI systems have resulted in many business solutions that allow for effective support of manager's work. Practice shows that the most significant business effects are obtained while using the following analyses offered by the BI systems:

- analysis that supports cross selling and up selling;

- customer segmentation and profiling;

- $\quad$ analysis of parameters importance;

- $\quad$ survival time analysis;

- analysis of customer loyalty and customer switching to competition;

- credit scoring;

- fraud detection;

- logistics optimisations;

- forecasting of strategic business processes development;

- web mining (analysis and assessment of the Internet services performance); and

- web-farming (analysis of the Internet content).

\section{Analysis that Supports Cross Selling and up Selling}

Marketing techniques of cross selling or up selling involve selling products to specific customers taking their previous purchases into consideration. Cross/up selling increases customer's trust in the company they deal with, and reduces the risk of customer's switching to competition. It leads to a remarkable increase in company's incomes and customer loyalty level. Data mining model helps to select marketing campaign objectives optimally and, what is more, show the best cross/up selling offers for customers in such a way that they correspond with customers' present needs. There are many advanced methods that are used to find interdependencies between purchased products. One of them - Market Basket Analysis - provides knowledge on what kind of services and products should be sold together in sets or which set should be recommended to a particular customer. Using classification models to select customers who are the most susceptible to a particular offer is another practical application of the discussed solution. It allows to direct marketing activities correctly and - as a result - to reduce costs of the campaign while simultaneously increasing its effectiveness.

\section{Customer Segmentation and Profiling}

Customer segmentation and profiling is based on grouping customers in some homogenous segments. BI systems enable both descriptive and predictive segmentation. Within descriptive segmentation the following segmentations are carried out:

- demographic segmentation (on the basis of the data including customer's income, age, sex, education, marital status, ethnic group, religion, etc.);

- behavioural segmentation (on the basis of the data including frequency of shopping, amount and sort of purchased products, etc.); and

- motivational segmentation (on the basis of variables that describe reasons of customers' purchases - this kind of data usually come from questionnaires and surveys carried out).

Subsequently, predictive segmentation is useful when it is necessary to distinguish 'good' customers from the 'bad' ones. At the very beginning, a variable that describes 'good' customers is determined (e.g. on the basis of total shopping they have done so far), and then, other variables that greatly influence the initial variable are determined. Such analyses allow to create a specific 
approach to a particular segment of customers, and this approach is supported by dynamic updating of segmentation and analyses of customers' migration between segments. Segmentation and profiling of customers together with identification of potential cross/up selling offers and testing of different hypotheses enable to create a customised offer that enjoys huge potential of meeting future, new and loyal customers' needs. Segmentation and profiling of customers provide some knowledge that is useful while designing new products and addressing marketing campaigns appropriately, as well. They allow for much more individualised customer service and optimisation of marketing activities and sales, thus deriving profits from data concerning customers.

\section{Analysis of Parameters Importance}

Analysis of parameters importance allows for determination of the most important (from the perspective of company's benefits) variables that describes products, processes and customers in the situation when there are different variables that describe analysed objects (Wijnhoven, 2001). Knowledge obtained this way is used to identify directions to be taken while perfecting products and customer service, and planning marketing actions, etc. The Bivariate statistical analysis, stepwise regression algorithm or artificial neuronal networks are mainly used in this case.

\section{Survival Time Analysis}

Survival time analysis evaluates customer's survival time length and a possibility that they leave during that time (leaving is understood as customer's switching to other supplier of a particular product). The analysis describes a distribution of survival time for individuals of a given population, monitors strength of other parameters impact on the expected survival time, and additionally, it enables to compare distributions of survival time between different sub-populations. Taking advantage of this method, a company may be given an invaluable insight into customer behaviour and find some ways to prolong customer's survival time.

\section{Analysis of Customer Loyalty and Customer Switching to Competition}

Analysis of customer loyalty usually concerns four categories: time of co-operation, amount (volume) of co-operation, closeness of co-operation and quality of co-operation. It is strictly related to analyses of customer's switching to competition. That results in identifying customers who are inclined to leave a company and join competition. Discovery of factors that result in switching to competition enables a company to direct - appropriately - its activities that aim at retaining customers. Moreover, distinguishing groups of customers characterised by different risk levels of leaving allows for construction of effective loyalty programmes and more attention paid to loyal customers.

\section{Credit Scoring}

Credit scoring models enable to determine financial risk that is related to particular customers. Such a process may be performed at the very moment a contract with a customer is concluded, and it is based on the data that come from application forms provided by a customer subject to analysis. Appropriate dealing with customers who are characterised by high risk of stopping payments makes it possible to reduce losses effectively. Credit scoring finds its application in, inter alia, banking (cash loans, assessment and tolerance of late payments) and in many other sectors related, for instance, to renting or leasing property and machinery. A good example of a credit scoring application may be also provided by contracts concluded to render telecommunications services connected with selling cellular phones. Credit scoring may be performed according to different models. Correct selection of the models depends on the analysis objective and specifics of the analysed data: 
- application scoring - used in case of new customers; information on them is available only on the basis of the completed application forms;

- behavioural scoring - paying attention to additional information on customers' track records; it predicts customers' future behaviour; and

- $\quad$ profit scoring - expanding of the basic scoring model; it pays attention not only to probability of paying credits back by customers, but also helps to assess what sort of profit may be expected as a result of co-operation with a particular customer; it is a more sophisticated model because it considers several additional economic factors.

\section{Fraud Detection}

Fraud detection is a well-tried and incredibly efficient method due to which a company may save vast amounts of money, and keep good relations with customers. Fraud detection means identification of suspicious transfers, orders and other illegal activities that target a company in question. Fraud detection models may be divided into application assessment and behavioural assessment. The former is used to detect suspicious customers at the early stage of signing a contract with a company in question, and is based on data derived from submitted applications. However, the latter is formulated on the basis of all data gathered during 'lifetime' of customer's activity including, inter alia, transactional data, use of services or performance track record. Fraud detection is frequently applied in order to prevent credit card frauds (e.g. Internet transaction frauds, telemarketing frauds or identity thefts), breaching of computer systems security, 'money laundering', telecommunications frauds, etc.

\section{Logistics Optimisations}

Logistics optimisation problem involves offering the best possible plan of logistics activities (including transportation or distribution), simultaneously taking already known limitations and available potential into consideration. Wrongly prepared plan of logistics optimisations may result in huge delays of e.g. production or distribution that would consequently bring about a necessity for bearing higher costs - thus decreasing potential profits to be obtained. Employing advanced data mining techniques, it is possible to show the best available solution for actual and complex optimisation problems. Quality of such solutions is usually much higher than the quality offered by traditional solutions of optimisation methods.

\section{Forecasting of Strategic Business Processes Development}

Abilities to understand and forecast development of strategic business processes make up a foundation of the correct planning of any business activity. That is why, modelling of multidimensional forecasts based on historical, present and anticipated data is so important. Analyses of time series make it possible to identify and analyse hidden trends and fluctuations (e.g. in marketing data or sales data). Taking seasonal nature and other marketing factors into consideration, it is possible to foresee potential behaviour of market or customers, developments of customer expectations and customers' purchases.

\section{Web Mining}

Analysis and assessment of the performance of Internet services (web mining) helps to obtain knowledge who uses services, when, why and how (Linoff, \& Berry, 2002; Thuraisingham, 2003). Application of advance classification, grouping, matching and regression models with reference to data on service performance and its users ('log' files), business data (databases), and data on users' experience with the service (questionnaires and interviews) allow to perform identification of customers and their preferences. Analysis and assessment of the performance of 
Internet services is limited to discovering and analysing information that is stored in the service (web content mining), discovering and analysing patterns of using the service by its users (web usage mining), and analysing service structure (web structure mining). This way, valuable, dialectic knowledge is acquired - the knowledge on company's offer attractiveness and its formulation in such a way that it corresponds to individual needs of particular customers. As a result, it is possible to customise service, automate navigation, shape pricing and promotional strategy and develop 'intelligent' e-business.

\section{Web-Farming}

Web-farming involves systematic analyses of the Internet content in order to provide a company with themes and issues of fundamental nature for company performance (Hackathorn, 1998). Internet is more and more frequently treated as a powerful resource of important economic information on potential customers, suppliers and competitors, information on the latest market bargains, technological trends and development of the world economy. Therefore, each company that wishes to remain its competitiveness must explore the web that is understood as a valuable source of knowledge. Web-farming offers a possibility of constant analysing of the Internet; finding important business information there; acquiring such information; saving it in data warehouse of a company; and delivering processed information to adequate persons or departments in a company. Major benefits obtained while carrying out web-farming include permanent monitoring of strategic business information sources, extracting of essential facts and their fluent matching with the internal system of company data storing. All these operations may be performed by means of advanced data mining tools.

\section{Conclusion}

Contemporary organisations have faced a necessity for complex and semi-structured decisionmaking. Dispersion of information sources and decentralisation of a decision making process result in insufficiency of present information management models. In this situation, organisations are offered the BI systems application. BI systems represent an integrated environment that mainly consists of data warehouses, ETL tools, OLAP techniques and data mining. Such an environment allows for carrying out numerous valuable business analyses that concern customers' behaviours. The environment makes it also possible to determine price fixing policies, forecast organisation development and optimise logistics activities. Potential areas of BI applications include Customer Relationship Management (Silva, \& Rahimi, 2004), sales analysis, profitability analysis, analysis of liabilities, cost monitoring, market segmentation, analysis of promotion and advertising campaigns, support of financial reporting, risk assessment and fraud investigation. Practice shows that BI may be mainly utilised for (Olszak, \& Ziemba, 2004):

1. Increase in the effectiveness of strategic, tactic and operational planning including first of all:

- modelling different variants in the development of an organisation;

- informing about the realisation of an enterprise's strategy, mission, goals and tasks;

- providing information on trends in an enterprise, results of introduced changes and realisation of plans;

- identifying problems and 'bottlenecks' to be tackled;

- providing analyses of "the best" and "the worst" products, employees, regions (as far as sales, costs or results are concerned);

- $\quad$ providing analyses of deviations from the realisation of plans for particular organisational units, individuals or indicators; and 
- $\quad$ providing information on the enterprise's environment e.g. on the sector an enterprise operates in, customers, competition or market trends.

2. Creating or improving relations with customers and in particular:

- $\quad$ providing sales representatives with adequate knowledge on customers so that they could rapidly meet their customers' needs; and

- following the level of customers' satisfaction together with efficiency of business practices and identifying market trends.

3. Analysing and improving business processes and operational efficiency of an organisation particularly by means of:

- $\quad$ providing knowledge and experience emerged while developing and launching new products onto the market;

- $\quad$ providing knowledge on particular business processes; and

- $\quad$ exchange of knowledge among research teams and corporate departments.

BI solutions that fulfil all the functions mentioned above provide an organisation with some opportunities to become an intelligent organisation.

Possibilities to refer to historical data carry out numerous multi-variant analyses and find yet unknown data interdependencies bring about higher and higher number of the BI system beneficiaries. Advantages of the BI applications have already been appreciated by trade companies, manufacturing sector, banks, financial sphere, telecommunications, government administration, etc. Forecasts show that the BI application market will belong - in the nearest time - to the most dynamically developing information technology markets. Therefore, users and designers of the BI systems will have to face new challenges. The former will have to learn how to analyse and practically utilise much information generated by the BI systems. The latter will have to develop BI technologies harmoniously and adequately to the needs voiced by organisations.

\section{References}

Bui, T. (2000). Decision support systems for sustainable development. In G. E. Kersten, Z. Mikolajuk, \& A. Gar-on Yeh (Eds.), Decision support systems for sustainable development. A resource book of methods and applications. Kluwer Academic Publishers.

Gray, P., \& Watson, H. (1998). Decision support in the data warehouse. Prentice Hall.

Gray, P. (2003). Business intelligence: A new name or the future of DSS. In T. Bui, H. Sroka, S. Stanek, \& J. Goluchowski, (Eds.), DSS in the uncertainty of the Internet age. Katowice: University of Economics.

Hackathorn, R. D. (1998). Web farming for the data warehouse. Morgan Kaufmann.

Hauke, K., Owoc, M. L., \& Pondel, M. (2003). Building data mining models in the Oracle 9i environment. Proceedings of Informing Science and IT Education, 2003. Santa Rosa: The Informing Science Institute. Retrieved December 1, 2005, from http://proceedings.informingscience.org/IS2003Proceedings/docs/146Hauke.pdf

Inmon, W. H. (1992). Building the data warehouse. New York: J. Wiley.

Kalakota, R. \& Robinson, M. (1999). E-business: roadmap for success. Addison-Wesley.

Kantardzic, M. (2002). Data mining: Concepts, models, methods and algorithms. New York: J. Wiley.

Kersten, G. E. (2000). Decision making and decision support. In G. E. Kersten, Z. Mikolajuk, \& A. Gar-on Yeh (Eds.), Decision support systems for sustainable development. A resource book of methods and applications. Kluwer Academic Publishers. 
Liautaud, B., \& Hammond, M. (2002). E-business intelligence. Turning information into knowledge into profit. New York: McGraw-Hill.

Linoff, G. S., \& Berry, M. J. A. (2002). Mining the web: transforming customer data into customer value. New York: J. Wiley.

Meyer, S. R. (2001, June). Which ETL tool is right for you?. DM Review Magazine.

Moss, L. T. \& Alert, S. (2003). Business intelligence roadmap - The complete project lifecycle for decision support applications. Addison-Wesley.

Olszak, C. M., \& Ziemba, E. (2003). Business intelligence as a key to management of an enterprise. Proceedings of Informing Science and IT Education, 2003. Santa Rosa: The Informing Science Institute. Retrieved December 1, 2005, from http://proceedings.informingscience.org/IS2003Proceedings/docs/109Olsza.pdf

Olszak, C. M., \& Ziemba, E. (2004). Business intelligence systems as a new generation of decision support systems. Proceedings of PISTA 2004, International Conference on Politics and Information Systems: Technologies and Applications. Orlando: The International Institute of Informatics and Systemics.

Poul, S., Gautman, N., \& Balint, R. (2003). Preparing and data mining with Microsoft SQL Server 2000 and Analysis Services. Addison-Wesley.

Power, D. (2001). Supporting decision-makers: An expanded framework. Proceedings of Informing Science and IT Education, 2001. Santa Rosa: The Informing Science Institute. Retrieved December 1, 2005, from http://proceedings.informingscience.org/IS2001Proceedings/pdf/PowerEBKSupp.pdf

Rasmussen, N., Goldy, P. S., \& Solli, P. O. (2002). Financial business intelligence. Trends, technology, software selection, and implementation. John Wiley \&Sons.

Reinschmidt, J., \& Francoise, A. (2000). Business intelligence certification quide. IBM, International Technical Support Organization.

Silva, R., \& Rahimi, I. (2004). Issues in implementing CRM: Acase study. Journal of Issues in Informing Science and Information Technology 2004(1). Santa Rosa: The Informing Science Institute. Retrieved December 1, 2005, from http://articles.iisit.org/133silva.pdf.

Thuraisingham, B. (2003). Web data mining and applications in business intelligence and counterterrorism. Auerbach Publications.

Turban, E., \& Aronson, J. E. (1998). Decision support systems and intelligent systems. Prentice Hall.

Viehland, D. (2005). ISExpertNet: Fcilitating knowledge sharing in the information systems academic community. Proceedings of Informing Science and IT Education, 2005. Santa Rosa: The Informing Science Institute. Retrieved October 12, 2005, from http://proceedings.informingscience.org/InSITE2005

Wells, J. D., \& Hess, T. J. (2004). Understanding decision-making in data warehousing and related decision support systems. An explanatory study of a customer relationship management application. In M. Raisinghani (Ed.), Business intelligence in the digital economy. London: Idea Group Publishing.

Wijnhoven, F. (2001). Models of information markets: Analysis of markets, identification of services, and design models. Informing Science: The International Journal of an Emerging Discipline, 4(4). Santa Rosa: The Informing Science Institute. Retrieved October 1, 2005, from http://inform.nu/Articles/Vol4/indexv4n4.htm 


\section{Biographies}

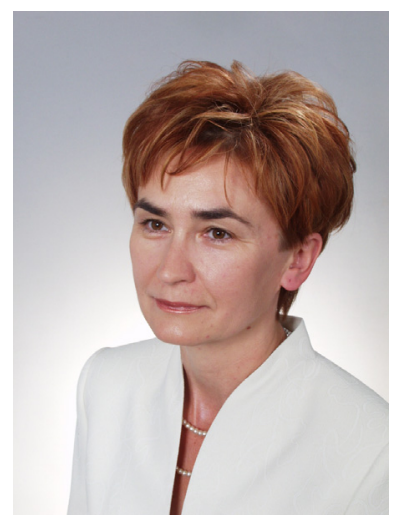

C. M. Olszak is a professor of Business Information Systems at University of Economics in Katowice. She holds MA in Information Systems from Technical University in Wrocław and $\mathrm{PhD}$ in Economics from University of Economics in Katowice.

Her special interests include Business Intelligence Systems, data warehouse, Decision Support Systems, knowledge management, e-business and multimedia and Internet technology.

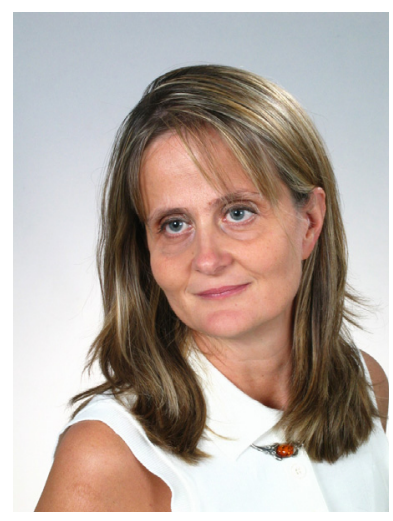

E. Ziemba is a doctor of Business Information Systems at University of Economics in Katowice. She holds MA in Cybernetics and Computer Science from University of Economics in Katowice and $\mathrm{PhD}$ in Economics from University of Economics in Katowice.

Her special interests include Knowledge Management Systems, Decision Support Systems, e-business and Internet technology. 